\title{
APPLICATION OF EXPERT SYSTEMS FOR MEASURING THE HUMIDITY OF BULK MATERIALS
}

\author{
E. Uljayev ${ }^{1}$, U.M. Ubaydullaev ${ }^{1}$, Sh.N. Narzullayev ${ }^{1}$, O.N. Norboyev ${ }^{2}$ \\ ${ }^{1}$ Tashkent State Technical University, Uzbekistan \\ ${ }^{2}$ Karshi Engineering and Economic Institute, Uzbekistan, \\ Email: narzullayevsh@tdtu.uz
}

\begin{abstract}
Measuring instruments for monitoring temperature, pressure, and other parameters are designed with large permissible errors in the range from 0.1 to $5 \div 10 \%$. In particular, for measuring instruments, express moisture measurements of bulk error tolerances are in the range of $\pm 0.5 \%$. The reason for such tolerances is associated with the difficulties of the methodology for ensuring the development and development of measuring and accounting mechanisms, both the change in the internal parameters of the device and the external parameters of the environment. The validity of the relevance of the work performed is associated with the need to develop modern measuring devices, that is, with the use of expert systems (ES) and artificial neural networks (ANN), which make it possible to create intelligent measuring devices. The work carried out the implementation of ANN in the mathematical package MATLAB 6.1, which shows the method of using an artificial neural network to create an intelligent device for an express method for measuring the moisture content of bulk materials, using the example of grain. After completing the preparatory stages, a neural network for measuring the moisture content of bulk materials was developed. As a result of the experiments carried out with three input parameters and updating the initial conditions, a learning curve was built that satisfies the main goal of learning ANN.
\end{abstract}

Keywords: Humidity, Control, Density, Temperature, Neural Network, Expert Systems, Tracing Structure.

\section{Introduction}

Now scientists of different areas develop and designed devices for temperature measurement, humidity, pressure, and other parameters. Unfortunately, now in some areas of production, admission to measurement errors too big. It fluctuates depending on the importance of the material and lies in the range from 0.1 to $5 \div 10 \%$. In particular, for measuring instruments of the express method for measuring the moisture content of bulk materials, the tolerance for measurement errors is within the range of $\pm 0.5 \%$. This is all due to the difficulty of methodological support of the measurement process and the development of measuring circuits and instruments with appropriate software that takes into account the influence of both changes in the internal parameters of the device and external environmental parameters.

Reduction of errors of control and management of parameters lead quality of the released products to increase, reduce defects, improve the relations clients, etc. All of those calls necessitates for development of measuring devices on a new basis, that is, using an ES built on the basis of artificial neural networks and neural network models, which make it possible to create intelligent measuring devices that take measurements taking into account significant disturbing parameters leading to measurement errors. The ongoing research and development work in this direction undoubtedly confirms the relevance of this work.

\section{Formulation of the Problem}

The main prospects of the use of ES using neural networks and neural network models are connected with the solution of difficult practical tasks. Measuring equipment in monitoring and control systems of ES are used to solve the following important tasks $[1,2]$ : optimization of the structure of construction of measuring systems, increasing the accuracy of measurement and regulation of parameters of production processes, etc. The solution of the problem using ES includes such stages as neural network model; formation of input and desired output signals of the NM; error signal generation, etc.

\section{Methodology for Solving the Problem}


As the main objectives of the resolved ES are considered as diagnosing, management of technological processes, modeling, planning, setup, and also plan and carrying out monitoring, training. In this work, the attempt to show the application of a possibility of ES for control, for example, of humidity of bulks is made.

The generalized block diagram of the applied ES is shown in Fig. 1. The base of the ES includes a system of logical conclusion, which applies information from the basis of knowledge (KB), generates recommendations for solving the desired problem. Also, production systems and semantic networks are used to represent knowledge in ES. If the ES establishes that the dispatch is accurate, in this case, the principle is recognized as optimal for this consultation will also rush into the process.

As the integral elements of each ES are considered as a node of receiving knowledge, a reflection node, and also explanations of the conclusions. In the bulk situations, the real ES in industrial operation function besides in the database (DB).

By means of this editor in $\mathrm{KB}$, new knowledge increases or is edited available, the user interface (UI). The SP is intended for interaction of ES with the user through which the system requests data, necessary for its work, and displays results.

In the structural diagram of ES, the main unit is the knowledge base and a subsystem of a logical output. Activity of ES is considered a preliminary stage receiving the initial facts - data. Basic data are the values of humidity, density, and temperature of controlled material described in the form of the binary code which arrive utilizing sensors, converters of humidity, temperature, and density.
Having chosen the maximum and minimum limits for changing these parameters, we can enter the values of temperature, density, and humidity from external sensors or devices, through the user interface, into the memory of the ES knowledge base. In the process of functioning, the ES reads the information from its knowledge base and tries to realize the logical conclusion of the decision of the task defined before it. There are two main types of records stored in the knowledge base:

1) facts - the limiting values of the parameters of humidity, temperature, and density in the form of a binary code, corresponding from $1.0 \%$ to $16 \%$; temperatures from $10{ }^{\circ} \mathrm{C}$ to $35{ }^{\circ} \mathrm{C}$ and density, describing the state of the controlled material, as well as;

2) the rules describing ways of the solution of a task. Let's note that all rules KB have the identical form of record and consist of two parts: condition and action.

As a processing rule of the actual data values of $\mathrm{KB}$, as well as other known works, we use various operations of Bays's function over logic variables. A main objective of creation of ES - receiving set (i.e. optimum) value of humidity.

After reading the initial data, the inference subsystem, consisting of the artificial origin of neural networks, starts displaying the knowledge base, and also alternately compares the problem presented with the knowledge base records that outline the decision process. If the criterion of the current $\mathrm{KB}$ rule is confirmed by a set of initial precedents, in this case the concept carries out the process written in this law, adding the latest output data to the KB.

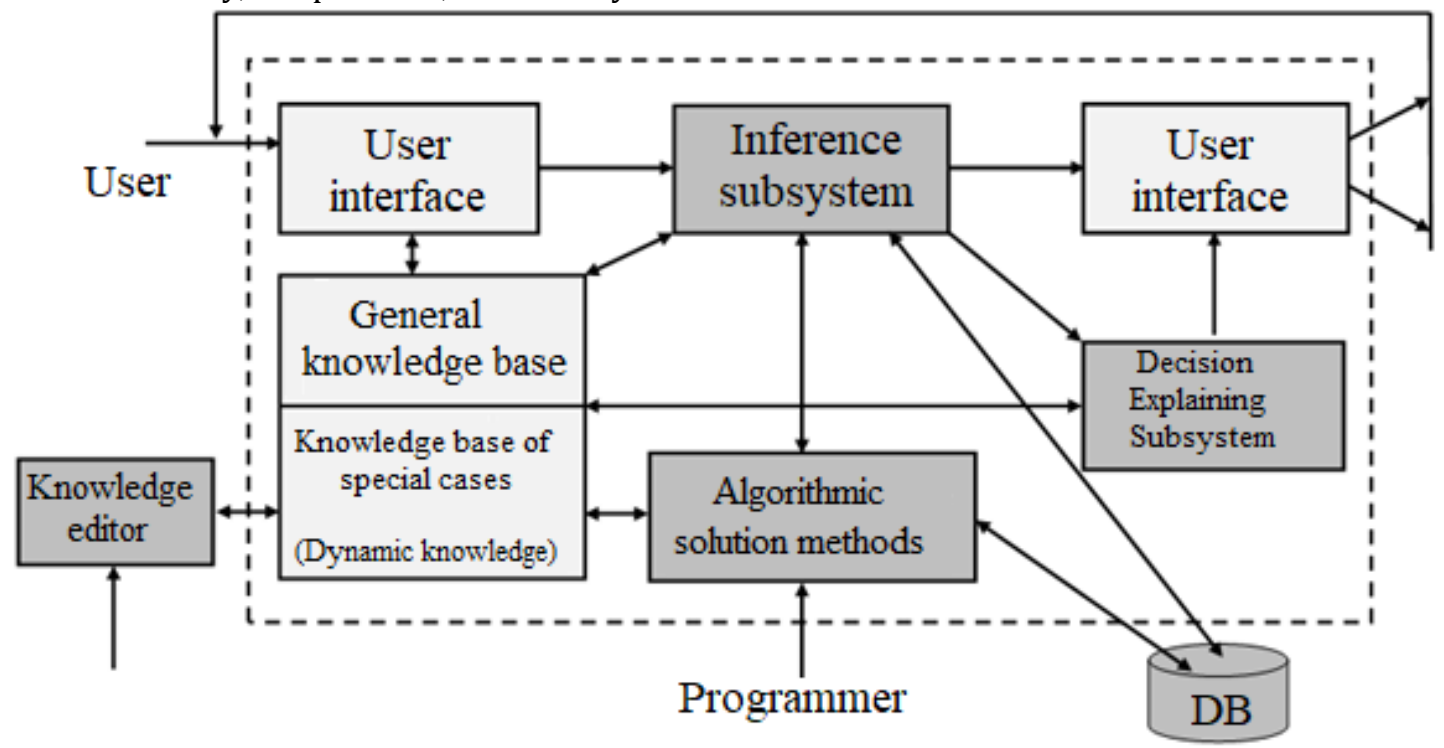

Figure 1: Generalized structure of the expert system

Considering the information above, the technology of comparison, search and information processing development of ES it is possible to provide the scheme including the following stages (fig. 2.): formalization technological processes of ES, creation in its framework of mathematical methods 
also algorithms of forming and processing of knowledge.

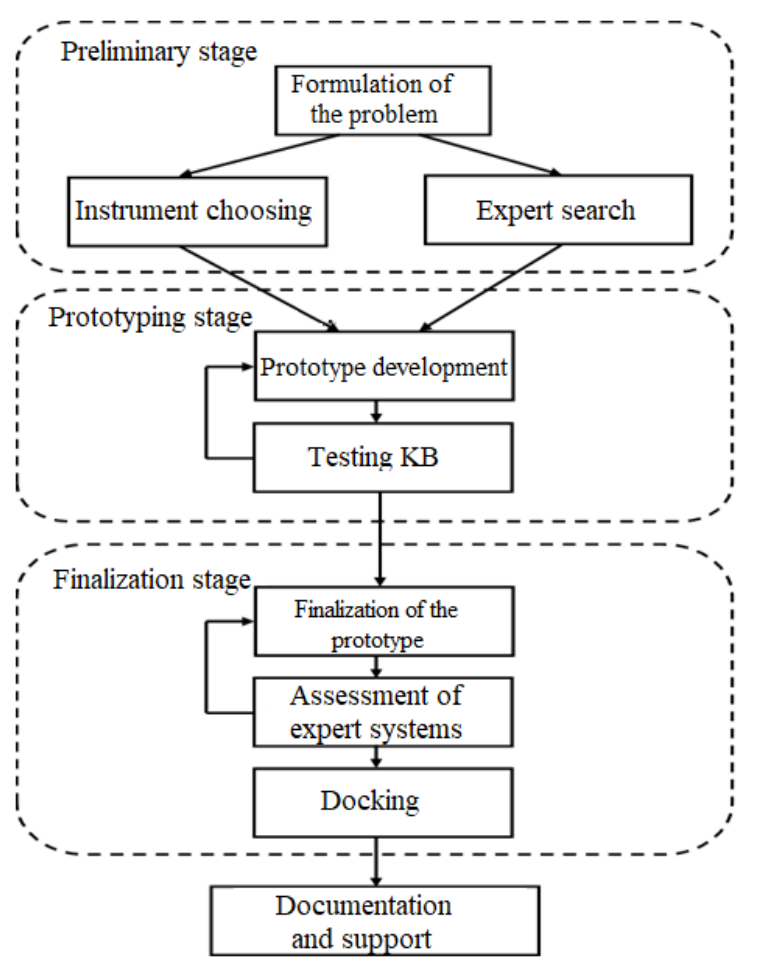

Figure 2: Stages of ES development

In the course of the problem statement, the most critical part of development, in general, is the right choice of a problem. To solve this issue, we used tools built on the programming language (Python). In the process of creating an ES prototype, the correctness of the coding of facts, connections, and strategies of the expert's reasoning in the knowledge base KB was performed.

After the choice of structure of ES solved a problem, i.e. connected to process (organization) of input, processing of input parameters, and path of achievement on the planned purpose.

So far, many research and practical works, using different versions of a mathematical MATLAB $[8,9]$ were performed in this direction. In this regard, an attempt is made in the work to show the method of using an artificial neural network ANN to create an intelligent device for an express method for measuring the moisture content of bulk materials, using the example of grain. The fundamentals of the theory and technology of using ANN are presented in the version of the package - MATLAB 6.1, containing a graphical user interface GUI for ANN.

Using the software NNTool and the technology of its application, we will solve the problem of synthesis of model the monitoring device of humidity of bulks [3, 8, 9]. Synthesis of the measurement humidity device is possible to apply INS without memory or with memory. Here, the key element is an ANN without memory, the role of which is determined by the fact that the neurons used with certain activation functions of the ANN are a universal approximator.

This means that within a given range of input variables, the ANN can reproduce and simulate the desired function with a given accuracy in a convenient form for the operator, i.e. in digital or graphic.

According to the given order of synthesis of ANN after the structure of ANN is selected, its parameters should be entered into the knowledge base. Methods of input of extreme values of input controlled parameters were described above. As for the desired values of the output signals of the NSM, we will determine them in the process of solving the selected optimization problem. In this procedure, the process of learning the ES knowledge base is carried out and the structure of the ANN is selected from a variety of lists and a set of learning algorithms for each type of neural network. To continue the ANN modeling, the issues related to working with NNTool are considered. After completing the list of the neural network measuring the moisture content of bulk materials.

It is known that at present, to measure the moisture content of bulk materials, capacitive methods are mainly used $[4,5,6,7,10,13,14,15]$. In capacitive converters of moisture meters of coaxial form, the equation of the dependence of the capacitance of the converter on external factors can be described in the following differential form:

$$
\begin{aligned}
& d C=\frac{\partial C}{\partial W} d W+\frac{\partial C}{\partial T} d T+\frac{\partial C}{\partial \Gamma} d \Gamma+ \\
& +\frac{\partial C}{\partial X} d X+\frac{\partial C}{\partial \Pi} d \Pi+\frac{\partial C}{\partial t} d t
\end{aligned}
$$

where C - cell capacity; W, T, $\Gamma, \mathrm{X}$ - humidity and temperature, particle size and chemical composition of controlled material; $\Pi$ - density of volume of controlled test; $\mathrm{t}$ - ambient temperature.

Obviously, the problem of measuring humidity will be solved the better, the more completely the moisture meter system as a whole ensures that the conditions are met:

$$
\begin{aligned}
& \frac{\partial C}{\partial W} \rightarrow \max \text { and } \\
& \sum\left(\frac{\partial C}{\partial T} ; \frac{\partial C}{\partial \Gamma} ; \frac{\partial C}{\partial X} ; \frac{\partial C}{\partial \Pi} ; \frac{\partial C}{\partial t} \rightarrow \min \right)
\end{aligned}
$$

In order to reduce the measurement error, the coefficients $\alpha_{1}, \alpha_{2}, \alpha_{3}, \ldots, \alpha_{\mathrm{n}}$ are introduced to correct these deviations. The values of these coefficients are determined experimentally.

The mathematical model of dependence of capacity of the measuring transducer on change of coefficients of the perturbing influences can be described in the following view: 


$$
C=\alpha_{W} W+\alpha_{T} T+\alpha_{\Gamma} \Gamma+\alpha_{X} X+\alpha_{\Pi} \Pi+\alpha_{t} t
$$

The analysis of the described methods and existing measuring instruments showed that these measuring instruments did not take into account external disturbances, for example, changes in temperature, the density of bulk materials, ambient humidity, etc., which directly affect the measurement errors.

As can be seen from this formula, humidity depends on the density of bulk materials, temperature, chemical composition, ambient temperature (AT), magnetic field level, etc. Among the listed parameters, the temperature of the AT and the level of the magnetic field can be neglected, since they can be minimized or eliminated by shielding, grounding, and ensuring the operating condition.

To solve the problem, we take the maximum value of the moisture content of bulk materials equal to "1" and the minimum value - "0". Hence, the number of input parameters is three, and the output parameter is one. According to these initial data, we create a neural network that performs logical "AND" functions.

According to $[8,9,11,12]$, we will choose a network consisting of one perceptron with three inputs. In the process of training the network, input data are supplied to its inputs, and the value obtained at the output is compared with the target (desired) one. Based on the comparison result (the deviation of the obtained value from the desired one), the values of the change in the weights and the bias are calculated, which reduce this deviation. Based on this, before creating a network, it is necessary to prepare a set of training and target data. Let's compose the truth table for the logical function "AND", where X1, X2, and X3 are inputs, and $\mathrm{Y}$ is the desired output (Table 1).

Table 1

\begin{tabular}{|c|c|c|c|}
\hline $\mathrm{X} 1$ & $\mathrm{X} 2$ & $\mathrm{X} 3$ & $\mathrm{Y}$ \\
\hline 0 & 0 & 0 & 0 \\
\hline 0 & 0 & 1 & 0 \\
\hline 0 & 1 & 0 & 0 \\
\hline 0 & 1 & 1 & 0 \\
\hline 1 & 0 & 0 & 0 \\
\hline 1 & 0 & 1 & 0 \\
\hline 1 & 1 & 0 & 0 \\
\hline 1 & 1 & 1 & 1 \\
\hline
\end{tabular}

Information can be represented by any formulation that MATLAB 6.1 understands.
To simulate a neural network with three inputs, we enter the initial data in the form shown in Fig. 3.

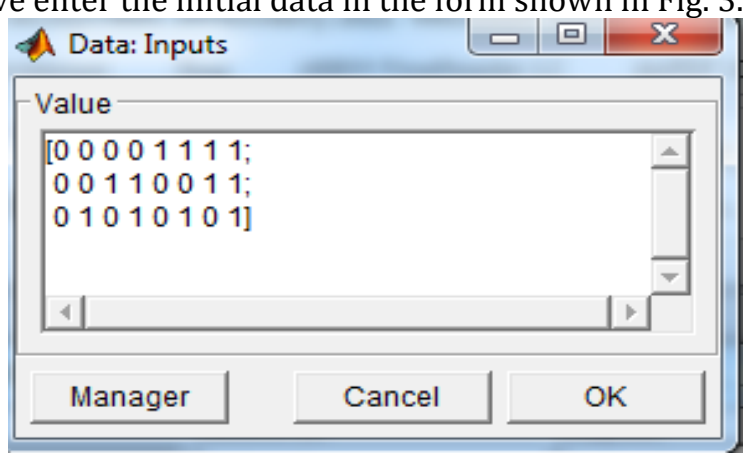

Figure 3: Initial data for ANN modeling

Then the window for creating a neural network modulated in the version of the package - MATLAB 6.1, will look like the following (Fig. 4).

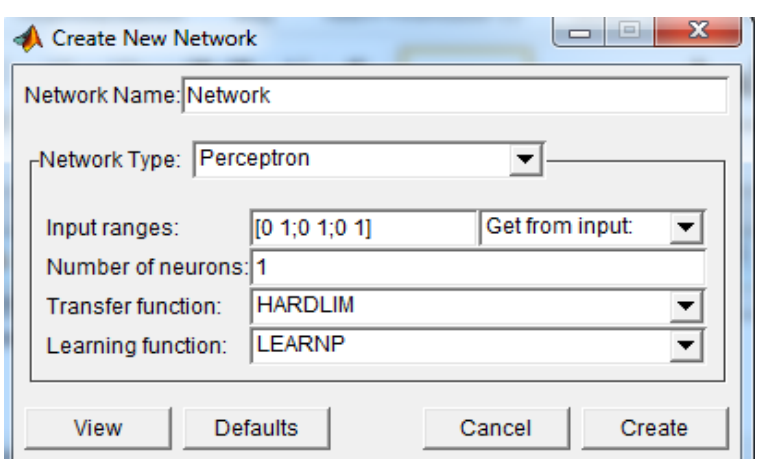

Figure 4: Window "Create a network"

Each line of information drawn in (Fig. 4) is a vector with two elements: the first is the minimum signal value that is fed to the corresponding input of the network during training, the second is the maximum. Note that in the process of modeling the ANN at its output, we must receive the value 00000001.

After all, you can see the architecture of the network is created, i.e. we have the opportunity to make sure that all actions were performed correctly. Figure 5. depicts a perceptron network with an output block. The number of neurons in the layer is one the network has three inputs. On one input, the values of two data are entered, and on the other one.

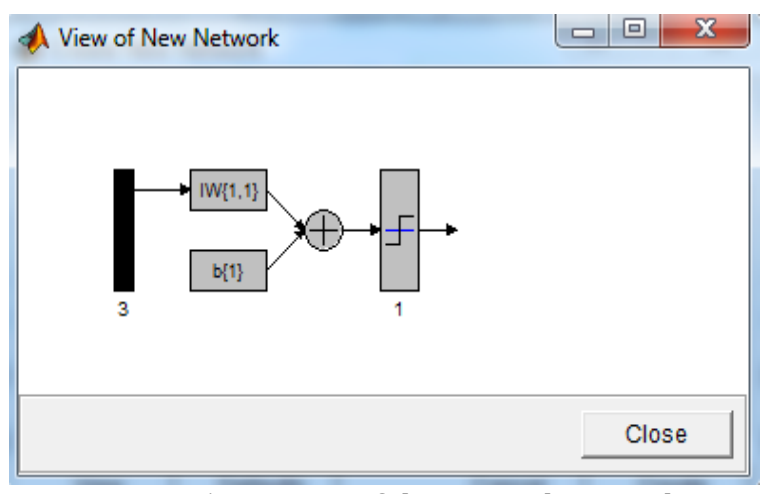

Figure 5: Preview of the created network 
As a result of these operations, an object named network1 will appear in the main window of NNTool. Analysis of the work performed shows that after the completed stage of creating a network, the result obtained will not immediately provide the correct answer. To achieve this goal, we continued to train the network with suitable fitted values. We completed the learning process by choosing criteria with the minimum error, i.e. with the output data equal to 00000001 . As a result, on the "Training parameters" tab of the network (Fig. 6) the following is set: the number of epochs; goal achievement, etc.

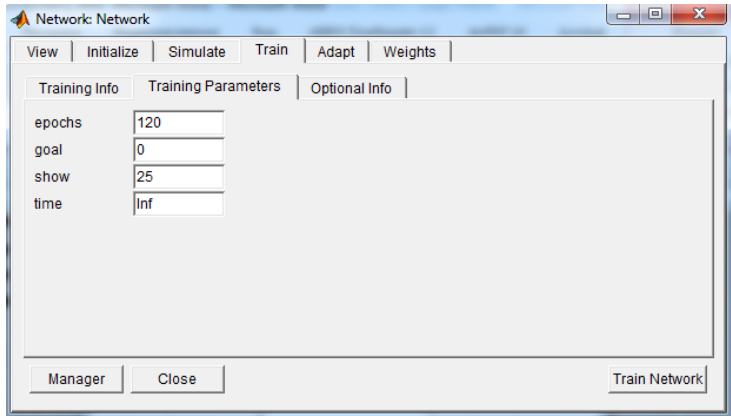

Figure 6: Tab of training parameters

Since our problem belongs to problems of the class with linearly separable sets, therefore, depending on the given goal, there is always an exact solution. Therefore, according to, you can set the threshold for achieving the goal equal to zero. Note that the training time field has an infinite time interval (Fig. 7).

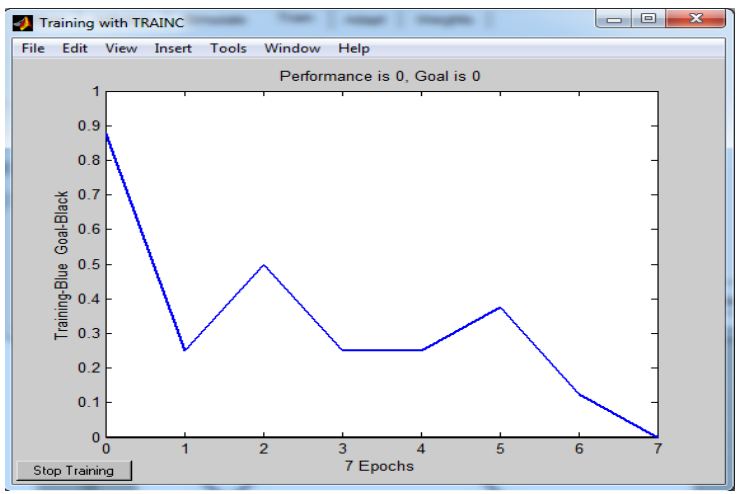

Figure 7: Learning curve

According to $[8,9,16]$, for perceptrons with a hard-constrained activation function, the error is calculated as the difference between the target and the resulting output. Thus, according to Fig. 7, we assume that the learning algorithm has found an exact solution to the problem.

For methodological purposes, let us make sure that the problem is solved correctly by running the trained network. Note that here the obtained values (value weights) and deviations (displacements) are set according to a predetermined permissible error, for example, $\pm 0.001 \%$ i.e. is initialized.

\section{Repetition of Experiments}

Since before each subsequent training experience is necessary to update the initial conditions, we carry out new experiments with the following values 10000,10110 , etc.

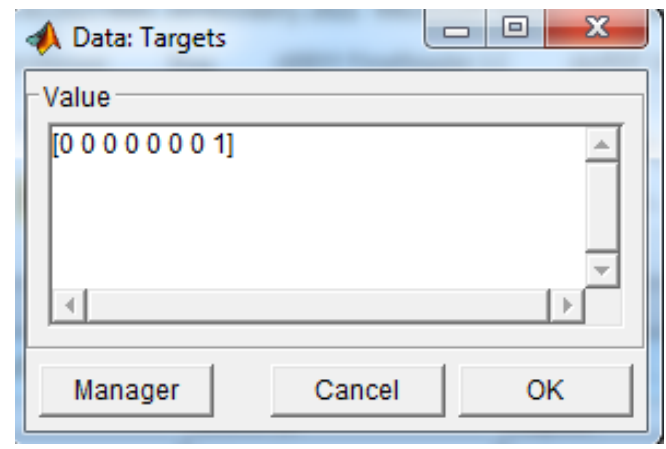

Figure 8: Expected target

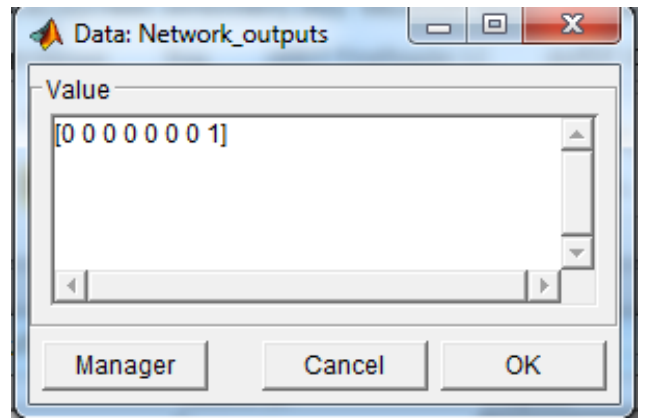

Figure 9: The result

Thus, we run a series of experiments with different networks before we get a suitable value of $\pm 0.001 \%$. As a result of the experiments carried out on the step of training the network, with different initial data, suitable values were obtained that satisfy the established criterion for the measurement accuracy (Fig. 6 and Fig. 7). The obtained values showed the inexpediency of changing the selected neural network model and the use of an additional test set of observations.

\section{Conclusions}

The relevance of the work performed is substantiated due to the need to develop promising devices, that is, using expert systems built based on artificial neural networks (ANNs), which make it possible to create intelligent measuring devices that carry out measurements taking into account significant disturbing parameters that affect the measurement errors. The tasks are described, which are solved when constructing the optimal structure of neural networks, including the stage of developing a neural network model. As a result of the experiments carried out on the step of training the network, with different initial data, suitable values 
were obtained that satisfy the selected criterion for the measurement accuracy.

\section{References}

[1] Kulakov M.V. Texnologicheskie izmereniya i pribori dlya ximicheskix proizvodstv[Technological measurements and devices for chemical production]. Izd. 3-ye, pererab. I dop. -M., «Mashinostroenie», 1983. $424 \mathrm{~s}$.

[2] Yusupbekov N.R., Muhamedov B.I., G'ulomov Sh.M. Texnologik jarayonlarni nazorat qilish va avtomatlashtirish [Control and automation of technological processes]. -T.: O'qituvchi, 2011. -576 b.

[3] Berliner M.A. Izmereniya vlajnosti[Measurement of humidity]. Izd. 2-ye, pererab. -M., «Energiya», 1973. $400 \mathrm{~s}$.

[4] Teoriya i praktika eksprescnogo kontrolya vlajnosti tverdix i jidkix materialov [Theory and practice of express control of moisture in solid and liquid materials]. Pod red. Ye.S. Krichevskogo. -M.: Energiya, 1980.

[5] Slikter Ch. Osnovi teorii magnitnogo rezonansa [The basis of the theory of magnetic resonance]. -M.: Mir, 1981.

[6] Uljaev E., Ubaydullaev U.M., Narzullaev Sh.N. (2020). Capacity transformer of coaxial and cylindrical form of humidity meter. Chemical Technology, Control and Management, №4(94), 2020. - pp. 23-30. journal homepage: https://uzjournals.edu.uz/ijctcm/vol2020/iss4 /4/

[7] Uljaev E., Narzullaev Sh.N., Erkinov S.M. Increasing calibration accuracy of the humidity control measuring device of bulk materials. Technical Science and Innovation, №3(05), 2020. -pp. 172-179. journal homepage: https://uzjournals.edu.uz/btstu/vol2020/iss3/ $23 /$

[8] Semeykin, V. D. Modelirovanie iskusstvennix neyronnix setey $\mathrm{v}$ srede MATLAB[Modeling of artificial neuronal networks in MATLAB environment] / V.D.Semeykin, A.V.Skupchenko // Vestnik Astraxanskogo gosudarstvennogo texnicheskogo universiteta / Seriya: Upravlenie, vichislitelnaya texnika i informatika. - 2009. № 1. - S. 159-164.

[9] N.R.Yusupbekov, R.A.Aliev, R.R.Aliev, A.N.Yusupbekov Intellektual'nye sistemy upravleniya i prinyatiya reshenij [Intelligent management and decision-making systems]. Tashkent: Uzbekiston millij ehntsiklopediyasi, 2014. 572 p. (in Russian).

[10] Uljaev E., Narzullaev Sh.N., Xaydarov F.G. K voprosu razrabotki intellektualnogo kombinirovannogo ustroystva kontrolya vlajnosti sipuchix materialov // Materiali mejdunarodnoy nauchnoy konferensii «Innovatsionnie resheniya injenerno- texnologicheskix problem sovremennogo proizvodstva». 2 TOM. 14-16 noyabrya 2019 g. Buxara-2019 [On the issue of developing an intelligent combined device for controlling the moisture content of bulk materials // Materials of the international scientific conference «Innovative solutions of engineering and technological problems of modern production». 2 vol. November 14-16, 2019 Bukhara-2019]. S.204-206.

[11] Uljayev E., T.Ravutov Sh., Ubaydullayev U.M. Remote control device to control the contact uniformity of the brush strippers on the spindle's surface of the cotton picking apparatus. "1st International Conference on Energetics, Civil and Agricultural Engineering 2020" 14-16 October 2020, Tashkent, Uzbekistan. IOP Conf. Series: Earth and Environmental Science 614 (2020) 012139. doi:10.1088/1755-1315/614/1/012139

[12] T.U.Umarov, U.T.Mardonov, O.A.Khasanov, Sh.O.Ozodova, B.D.Yusupov. Research on the variation of firmness of pointed drills by the method of simulation modeling of the process of wear, International Journal of Psychosocial Rehabilitation, volume 24, issue 4. https://www.psychosocial.com/article/PR201 298/12155/.

[13] E.Uljaev, U.M.Ubaydullaev, Sh.N.Narzullaev, E.F.Xudoyberdiev, F.G.Haydarov. (2020). Classification of Detectors of Capacitive Humidity Transducers of Bulk Materials. International Journal of Advanced Science and Technology, 29(11s), 1949 - 1953. Retrieved from

http://sersc.org/journals/index.php/IJAST/arti cle/view/21858

[14] Uljaev E., Ubaydullaev U.M., Narzullaev Sh.N. (2020). Optimization of the sizes of the cylindrical measuring transducer. Chemical Technology, Control and Management, № 56(95-96). - pp. 29-33. journal homepage: https://uzjournals.edu.uz/ijctcm/vol2020/iss5 L5/

[15] Umarov E.O., Mardonov U.T., Shoazimova U.Kh., Influence of the Magnetic Field on the Viscosity Coefficient of Lubricoolant that is used in the Cutting Proces, International Journal of Mechatronics and Applied Mechanics, 2020, Issue 8, Vol. II. pp. 144-149 https://www.doi.org/10.17683/ijomam/issue8 .50

[16] E.Ulzhaev, Sh.N.Narzullaev, O.N.Norboev. Substantiation of Application of Artificial Neural Networks for Creation of Humidity Measuring Devices. International Vritual Conference On Innovative Thoughts, Research Ideas and Inventions in Sciences Hosted from Newyork, USA, January 20, 2021, -pp. 86-91. 
http://papers.euroasiaconference.com/index.p $\mathrm{hp} / \mathrm{eac} /$ article/view/28 